\title{
A New Approach of Syrup Manufacturing Using Fuzzy Time Control Discrete Event System
}

\author{
Syed Fazil Bin Farukh and M. Saleem Khan
}

\begin{abstract}
Pharmaceutical industries of world are manufacturing their most of the goods in syrup form. The proposed study relates with the designing of medicated syrup manufacturing using the fuzzy time control discrete event system. The system is designed with three inputs; viscosity, specific gravity, and chemical selection. And eight outputs temperature, temperature time, mixing speed, mixing time, valve, valve opening time, $\mathrm{PH}$ at current liquid temperature, and PH time. System is controlled by controlling the four parameters; valve selection, temperature monitoring unit, mixing motor, and PH control unit. System takes feed back from four sensors and time control rules are formulated and simulated using MATLAB tool box.
\end{abstract}

Index Terms-Discrete event, fuzzy time control, MATLAB simulation, syrup manufacturing.

\section{INTRODUCTION}

Syrup is the aqueous pharmaceutical preparation having the concentrated sugar solution with active and non-active ingredients. These preparations are manufactured by pharmaceutical industries following the standards of British and European pharmacopoeias in the whole world. The syrup solutions are characterized by parameters temperature, specific gravity, $\mathrm{pH}$, and viscous consistency. [1]-[5] the proposed syrup manufacturing model is designed by using fuzzy time control discrete event system in which output variables are time dependent and discussed with non probabilistic uncertainty issues [1] and controller work on heuristic knowledge [6] controller operate the plant $\mathrm{ON}$ or OFF for a specific period of time. Design system has flexibility to easily adjust the input and output parameters according to the mixture requirement.

\section{FuZZY TIME CSCRETONTROL DitCRETE EVENT SySTEM}

Fuzzy time control discrete event system is modified form of fuzzy logic controls system, which is basically combination of two different systems. One is discrete event system and the other is fuzzy time control system. This system contains Fuzzifiers, inference engine, knowledge base (which contains data base, rule base, and output membership functions), defuzzifiers, and discrete event system [7].

Manuscript received October 22, 2012; revised November 25, 2012.

Syed Fazil Bin Farukh is with Central h-Tech Lab, University of Agriculture Faisalabad (e-mail: harisali4@yahoo.com)

M. Saleeem Khan is with the Department of Computer Science, Gc University Lahore (e-mail: mskgcu@yahoo.com)
Three inputs; viscosity, specific gravity, and chemical selection are used for the designed syrup manufacturing system. Three numeric input values are given to three Fuzzifiers. After receiving numeric values of inputs these Fuzzifiers convert them into linguistic variables. These linguistic variables are then given to inference engine where the max-min composition is applied and gives eight values of R,s. Knowledge base provides eight singleton values according to the fuzzy rules designed for the proposed syrup manufacturing system after getting the crisp values. Defuzzifiers get eight values from inference engine and eight from knowledge base at its input and give the eight crisp values at its output. Here eight defuzzifiers are used, four for output variable; temperature, mixing speed, PH, valve selection and four for output time; temperature time, mixing time valve opening time, and PH time [7]. The values of out variables are converted into binary codes using analog to digital converter (ADC) and decoder and crisp values of output time; temperature time, mixing time valve opening time, and $\mathrm{PH}$ time are provided to the pulse strobe units which provides the time pulses. These time pulses allow the binary codes to pass for a specific period of time. Then these binary codes are used to make active discrete event system under time constrain [8].

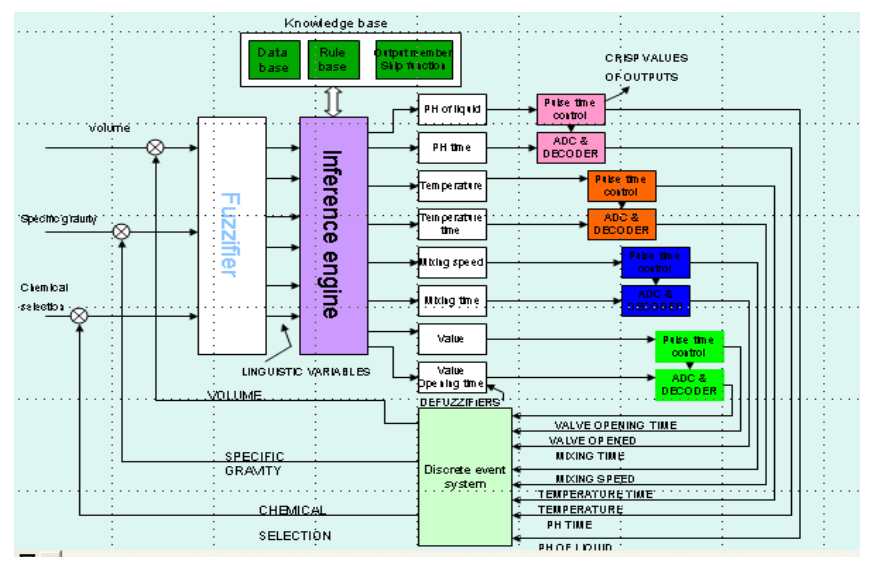

Fig. 1. Experimental arrangement of Syrup manufacturing fuzzy time control discrete event system

\section{Design Algorithm}

The syrup manufacturing system is designed with three inputs viscosity specific gravity and chemical selection and eight outputs temperature, temperature time, valve, valve opening time, $\mathrm{PH}$ at current liquid temperature, $\mathrm{PH}$ time, mixing speed, mixing time, each input plot contains six membership functions and five regions the name of membership functions their ranges are shown in table-I 
TABLE I: INPUT MF AND THEIR RANGES

\begin{tabular}{llll}
\hline \hline $\begin{array}{l}\text { Membership } \\
\text { Function }\end{array}$ & $\begin{array}{l}\text { Viscosity } \\
\text { dyn·s/cm }\end{array}$ & $\begin{array}{l}\text { Specific } \\
\text { Gravity } \\
\mathrm{Mg} / \mathrm{ml}\end{array}$ & $\begin{array}{l}\text { Chemical } \\
\text { selection }\end{array}$ \\
\hline Very small & $0-1$ & $0-1$ & $0-10$ \\
Small & $0-2$ & $0-2$ & $0-20$ \\
Medium & $1-3$ & $1-3$ & $10-30$ \\
Above medium & $2-4$ & $2-4$ & $20-40$ \\
High & $3-5$ & $3-5$ & $30-50$ \\
Very high & $4-5$ & $4-5$ & $40-50$ \\
\hline \hline
\end{tabular}

In response of chemical selection valve are open, installed at the feed lines for material constituents flow.

Plot of input membership functions (MF). For viscosity is shown in the Fig. 2 there are six membership functions $F_{1}[1] F_{1}[2] F_{1}[3] F_{1}[4] F_{1}[5] F_{1}[6]$ and five regions

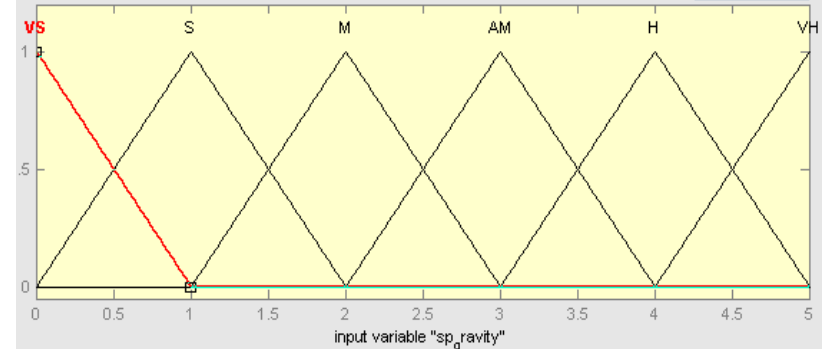

Fig. 2. Input MF function specific gravity plot

Plot of input MF viscosity contains six MF, s $\mathrm{F}_{2}[1], \mathrm{F}_{2}[2]$, $\mathrm{F}_{2}$ [3], $\mathrm{F}_{2}$ [4], $\mathrm{F}_{2}$ [5], $\mathrm{F}_{2}$ [6] and five regions input numeric value of viscosity lies in any one of the five region as shown in Fig. 3.

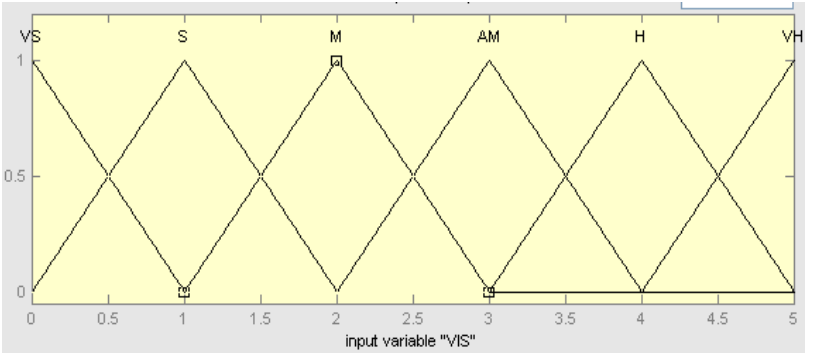

Fig. 3. Input MF plot for viscosity

Plot of input MF chemical selection contains six MF,s
$F_{3}[1] F_{3}[2], F_{3}[3], F_{3}[4], F_{3}[5], F_{3}[6]$ and five regions as shown in Fig. 4

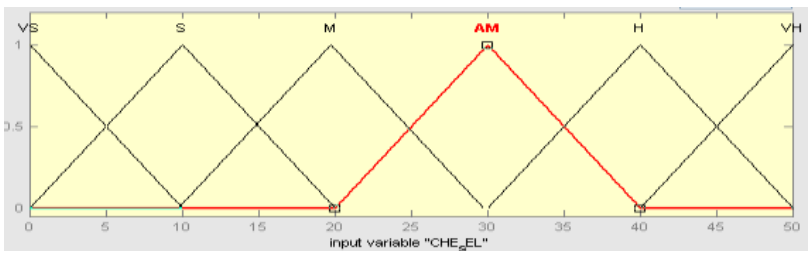

Fig. 4. Input MF plot of chemical selection

Plot of output MF are shown in Fig. 5 for the convenience in calculation the range values of output membership function for mixing speed, mixing time, valve selection, valve opening time, $\mathrm{PH}$ at given temperature, $\mathrm{PH}$ time, Temperature, Temperature time are taken same, plot contains five output MF, s and four regions

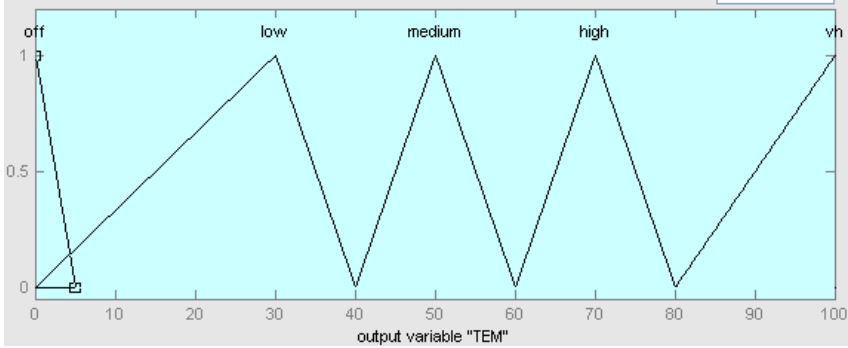

Fig. 5. Output MF plot

Output membership functions and their ranges are listed in the Table II.

To verify the design model of syrup manufacturing the input fuzzy variable value are taken; viscosity $=1.4$, specific gravity $=1.7$ and chemical selection $=16$ this value of viscosity lies in the first half of second region and maps with the fuzzy variable medium and small, medium is taken as $\mathrm{F}_{1}[3]$ and small is taken as $\mathrm{F}_{1}$ [2] the value of specific gravity lies in the second half of the second region and maps with the fuzzy variable medium and small, medium is taken as $F_{2}[3], F_{2}$ [2]. Selected value of chemical selection lies in the send half of second region and maps with the fuzzy variable medium and small, medium is taken as $\mathrm{F}_{3}[3], \mathrm{F}_{3}$ [2]. Fuzzifier result for this model are shown in Table III.

TABLE II: OUTPUT MEMBERSHIP FUNCTIONS AND THEIR RANGES

\begin{tabular}{|c|c|c|c|c|c|c|c|c|c|}
\hline $\begin{array}{l}\text { Membership } \\
\text { Function }\end{array}$ & Range & Temperature & $\begin{array}{l}\text { Temperature } \\
\text { Time }\end{array}$ & $\mathrm{PH}$ & PH time & Valve & $\begin{array}{l}\text { Valve } \\
\text { Opening } \\
\text { time }\end{array}$ & $\begin{array}{l}\text { Mixing } \\
\text { Speed }\end{array}$ & $\begin{array}{l}\text { Mixing } \\
\text { Time }\end{array}$ \\
\hline MF1 & $0-5$ & Off & None & Small & None & None & None & Stop & None \\
\hline MF2 & $0-40$ & Low & Small & Normal & Small & Few & Small & Slow & Small \\
\hline MF3 & $40-60$ & Medium & Medium & Medium & Medium & Medium & Medium & Medium & Medium \\
\hline MF4 & $60-80$ & High & Long & High & Long & Large & Long & Fast & Long \\
\hline MF5 & $80-100$ & Very high & Very long & $\begin{array}{l}\text { Very } \\
\text { high }\end{array}$ & Very long & Very large & Very long & Very fast & Very long \\
\hline
\end{tabular}

Inference engine take values from the Fuzzifier and apply min-max composition and gives the eight values; $R_{1}, R_{2}, R_{3}$, $\mathrm{R}_{4}, \mathrm{R}_{5}, \mathrm{R}_{6}, \mathrm{R}_{7}$, and $\mathrm{R} 8$.

$$
\begin{aligned}
& \mathrm{R}_{1}=\mathrm{F}_{1}[3]^{\wedge} \mathrm{F}_{2}[3]^{\wedge} \mathrm{F}_{3}[3]=0.4^{\wedge} 0.3^{\wedge} 0.4=0.3 \\
& \mathrm{R}_{2}=\mathrm{F}_{1}[2]^{\wedge} \mathrm{F}_{2}[3]^{\wedge} \mathrm{F}_{3}[3]=0.6^{\wedge} 0.3^{\wedge} 0.4=0.3
\end{aligned}
$$

$\mathrm{R}_{3}=\mathrm{F}_{1}[3]^{\wedge} \mathrm{F}_{2}[2]^{\wedge} \mathrm{F}_{3}[3]=0.4^{\wedge} 0.7^{\wedge} 0.4=0.4$
$\mathrm{R}_{4}=\mathrm{F}_{1}[2]^{\wedge} \mathrm{F}_{2}[2]^{\wedge} \mathrm{F}_{3}[3]=0.6^{\wedge} 0.7^{\wedge} 0.4=0.4$
$\mathrm{R}_{5}=\mathrm{F}_{1}[3]^{\wedge} \mathrm{F}_{2}[3]^{\wedge} \mathrm{F}_{3}[2]=0.4^{\wedge} 0.3^{\wedge} 0.6=0.3$
$\mathrm{R}_{6}=\mathrm{F}_{1}[2]^{\wedge} \mathrm{F}_{2}[3]^{\wedge} \mathrm{F}_{3}[2]=0.6^{\wedge} 0.3^{\wedge} 0.6=0.3$
$\mathrm{R}_{7}=\mathrm{F}_{1}[3]^{\wedge} \mathrm{F}_{2}[2]^{\wedge} \mathrm{F}_{3}[2]=0.4^{\wedge} 0.7^{\wedge} 0.6=0.4$
$\mathrm{R}_{8}=\mathrm{F}_{1}[2]^{\wedge} \mathrm{F}_{2}[2]^{\wedge} \mathrm{F}_{3}[2]=0.6^{\wedge} 0.7^{\wedge} 0.6=0.6$

$\mathrm{R}_{3}=\mathrm{F}_{1}[3]^{\wedge} \mathrm{F}_{2}[2]^{\wedge} \mathrm{F}_{3}[3]=0.4^{\wedge} 0.7^{\wedge} 0.4=0.4$

$\mathrm{R}_{5}=\mathrm{F}_{1}[3]^{\wedge} \mathrm{F}_{2}[3]^{\wedge} \mathrm{F}_{3}[2]=0.4^{\wedge} 0.3^{\wedge} 0.6=0.3$

$\mathrm{R}_{6}=\mathrm{F}_{1}[2]^{\wedge} \mathrm{F}_{2}[3]^{\wedge} \mathrm{F}_{3}[2]=0.6^{\wedge} 0.3^{\wedge} 0.6=0.3$

$\mathrm{R}_{8}=\mathrm{F}_{1}[2]^{\wedge} \mathrm{F}_{2}[2]^{\wedge} \mathrm{F}_{3}[2]=0.6^{\wedge} 0.7^{\wedge} 0.6=0.6$ 
In the output MF plot there are two overlapping regions and system takes three inputs so there are eight rules are design for this system [9] which are listed in the Table IV.

Singleton values obtained from knowledge base for applied rule are listed in Table V.

Output crisp values are obtained by defuzzification. There are many methods used for defuzzification e.g. (MOM) mean of maximum. (SOM) smallest of maximum (LOM) left of maximum etc.

The method use in this paper for defuzzification is (COA) center of average

Whose mathematical form is

$$
\sum_{i} S i \times R i / \sum R i
$$

where $i=1,2,3,4,5,6,7,8$

\begin{tabular}{|c|c|c|c|}
\hline $\begin{array}{l}\text { Input } \\
\text { Variable }\end{array}$ & $\begin{array}{l}\text { Value of } \\
\text { input }\end{array}$ & Region & $\begin{array}{l}\text { Fuzzy set } \\
\text { Calculation }\end{array}$ \\
\hline Viscosity & 1.4 & $2^{\text {nd }}$ & $\begin{array}{l}F 1[3]=0.4 \\
F_{1}[2]=1-F_{1}[ \\
3] \\
=0.6\end{array}$ \\
\hline $\begin{array}{l}\text { Specific } \\
\text { Gravity }\end{array}$ & 1.7 & $2^{\text {nd }}$ & $\begin{array}{l}\mathrm{F} 2[3]=0.3 \\
\mathrm{~F}_{2}[2]=1-\mathrm{F}_{2}[ \\
3] \\
=0.7\end{array}$ \\
\hline $\begin{array}{l}\text { Chemical } \\
\text { Selection }\end{array}$ & 17 & $2^{\text {nd }}$ & $\begin{array}{l}\mathrm{F} 3[3]=0.4 \\
\mathrm{~F}_{3}[2]=1-\mathrm{F}_{3}[ \\
3] \\
=0.6\end{array}$ \\
\hline
\end{tabular}

TABLE IV: DESIGN RULES FOR SYSTEM

\begin{tabular}{|c|c|c|c|c|c|c|c|c|c|c|c|}
\hline NO. & Viscosity & $\begin{array}{l}\text { Specific } \\
\text { gravity }\end{array}$ & $\begin{array}{l}\text { Chemical } \\
\text { Selected }\end{array}$ & Temp. & Temp . tim & & $\begin{array}{l}\text { Mixing } \\
\text { Speed }\end{array}$ & $\begin{array}{l}\text { Mixing } \\
\text { Time }\end{array}$ & Valve & $\begin{array}{l}\text { Valve } \\
\text { Opening } \\
\text { time }\end{array}$ & PH \\
\hline 1 & Small & Small & Medium & Low & Long & & Fast & Long & Few & Long & Mediu \\
\hline 2 & Medium & Small & Medium & Low & Medium & & Fast & Medium & Few & Medium & Norm \\
\hline 3 & Small & Medium & Medium & Medium & Long & & Very fast & Long & Few & Long & Medil \\
\hline 4 & Medium & Medium & Medium & Medium & Medium & & Very fast & Medium & Few & Medium & Norm \\
\hline 5 & Small & Small & Small & Low & Long & & Fast & Long & Medium & Long & Medil \\
\hline 6 & Medium & Small & Small & Low & Medium & & Fast & Medium & Medium & Medium & Norm \\
\hline 7 & Small & Medium & Small & Medium & Long & & Very fast & Long & Medium & Long & Mediu \\
\hline \multirow[t]{11}{*}{8} & Medium & Medium & Small & Medium & Medium & & Very fast & Medium & Medium & Medium & Norm \\
\hline & & \multicolumn{10}{|c|}{ TABLE V: SINGLETON VALUES } \\
\hline & & $\begin{array}{l}\text { Singleton } \\
\text { Value }\end{array}$ & TEMP. & $\begin{array}{l}\text { Temp } \\
\text { time }\end{array}$ & $\begin{array}{l}\text { Mixing } \\
\text { Speed }\end{array}$ & $\begin{array}{l}\text { Mixin } \\
\text { Time }\end{array}$ & Valve & $\begin{array}{l}\text { Valve } \\
\text { Opening } \\
\text { Time }\end{array}$ & $\mathrm{PH}$ & PH time & \\
\hline & & $\mathrm{S}_{1}$ & 0.3 & 0.7 & 0.7 & 0.7 & 0.3 & 0.7 & 0.5 & 0.7 & \\
\hline & & $\mathrm{S}_{2}$ & 0.3 & 0.5 & 0.7 & 0.5 & 0.3 & 0.5 & 0.3 & 0.5 & \\
\hline & & $\mathrm{S}_{3}$ & 0.5 & 0.7 & 1 & 0.7 & 0.3 & 0.7 & 0.5 & 0.7 & \\
\hline & & $\mathrm{S}_{4}$ & 0.5 & 0.5 & 1 & 0.5 & 0.3 & 0.5 & 0.3 & 0.5 & \\
\hline & & $\mathrm{S}_{5}$ & 0.3 & 0.7 & 0.7 & 0.7 & 0.5 & 0.7 & 0.5 & 0.7 & \\
\hline & & $\mathrm{S}_{6}$ & 0.3 & 0.5 & 0.7 & 0.5 & 0.5 & 0.5 & 0.3 & 0.5 & \\
\hline & & $\mathrm{S}_{7}$ & 0.5 & 0.7 & 1 & 0.7 & 0.5 & 0.7 & 0.5 & 0.7 & \\
\hline & & $\mathrm{S}_{8}$ & 0.5 & 0.5 & 1 & 0.5 & 0.5 & 0.5 & 0.3 & 0.5 & \\
\hline
\end{tabular}

TABLE VI: MATLAB SimULATION RESULTS

\begin{tabular}{cccccccc}
\hline \hline & $\begin{array}{c}\text { Temperatur } \\
\mathrm{e}\end{array}$ & $\begin{array}{c}\text { Temperat } \\
\text { ure } \\
\text { Time }\end{array}$ & PH & PH time & Valve & $\begin{array}{c}\text { Valve } \\
\text { Opening } \\
\text { time }\end{array}$ & $\begin{array}{c}\text { Mixing } \\
\text { speed }\end{array}$ \\
\hline $\begin{array}{c}\text { MATLAB } \\
\text { simulation results } \\
\begin{array}{c}\text { Designed system } \\
\text { values }\end{array}\end{array}$ & 40 & 61 & 34 & 61 & 31.1 & 61 & 84.4 \\
Time & 51 & 56 & 59.8 \\
\hline \hline
\end{tabular}

This system takes sixteen inputs to each defuzzifier eight from inference engine i.e. $\mathrm{R}_{1}, \mathrm{R}_{2}, \mathrm{R}_{3}, \mathrm{R}_{4}, \mathrm{R}_{5}, \mathrm{R}_{6}, \mathrm{R}_{7}, \mathrm{R}_{8}$ and eight from the rule base i.e. $\mathrm{S}_{1}, \mathrm{~S}_{2}, \mathrm{~S}_{3}, \mathrm{~S}_{4}, \mathrm{~S}_{5}, \mathrm{~S}_{6}, \mathrm{~S}_{7}, \mathrm{~S}_{8}$ and gives the crisp value of outputs[10-12]. MATLAB simulation result for this system are shown in the Fig. 6 below

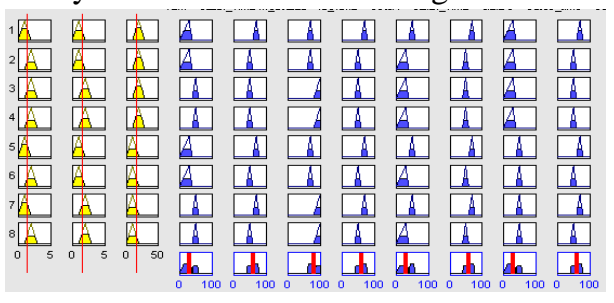

Fig. 6. MATLAB simulation rule viewer
From MATLAB simulation and also the defuzzified values from manual calculation corresponding to the input variable viscosity $=1.4$, specific gravity $=1.7$ and chemical selected $=16$.

\section{RESUlT DiscusSION}

MATLAB simulation results for the proposed syrup manufacturing model are shown in figure 7.

Fig. 7(a) Shows that temperature depends on viscosity and does not depend on specific gravity 


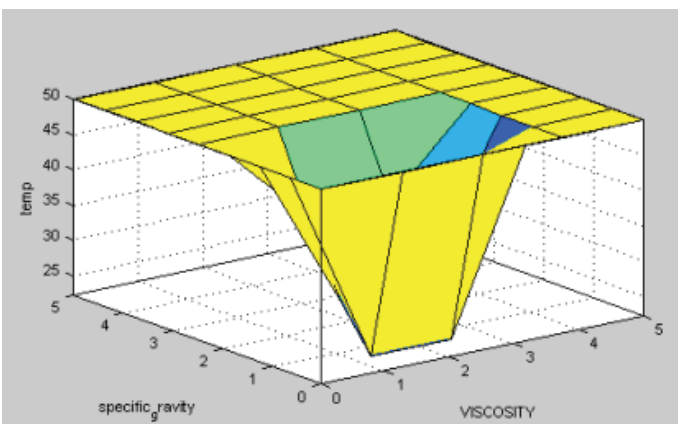

Fig. 7(a) Plot between specific gravity viscosity and temperature

Fig. 7(b) shows that cooling/ heating time does not depend on specific gravity it depend on the viscosity.

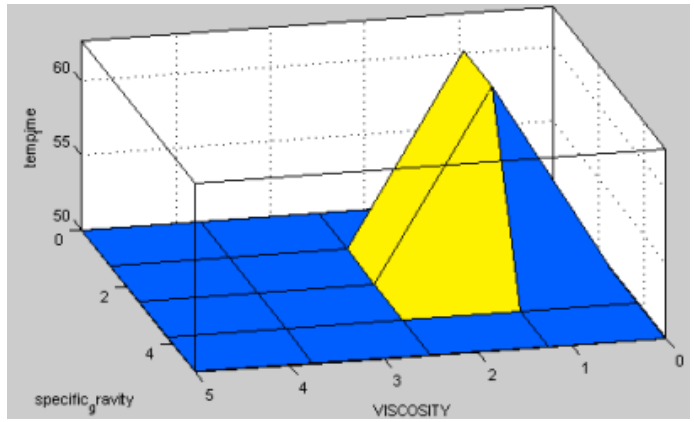

Fig. 7(b) Plot between specific gravity, viscosity and temperature time

Fig. 7(c) Shows that mixing speed does not depend on viscosity depends on specific gravity.

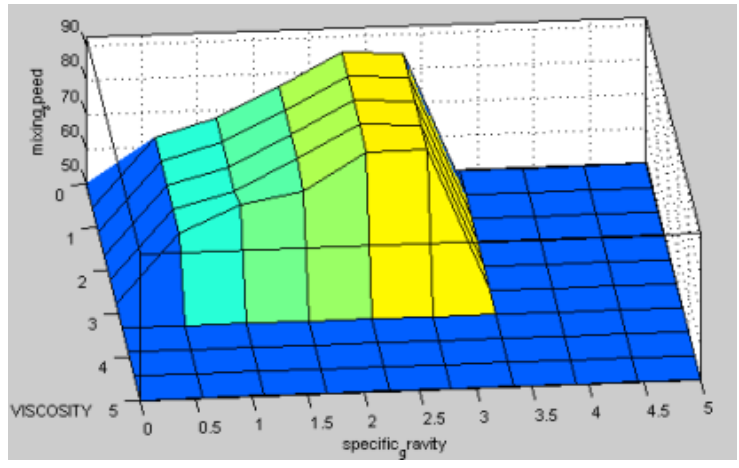

Fig. 7(c) Plot between specific gravity, viscosity and mixing speed

Fig. 7(d) Shows that rotating time depend on viscosity it does not depend on specific gravity.

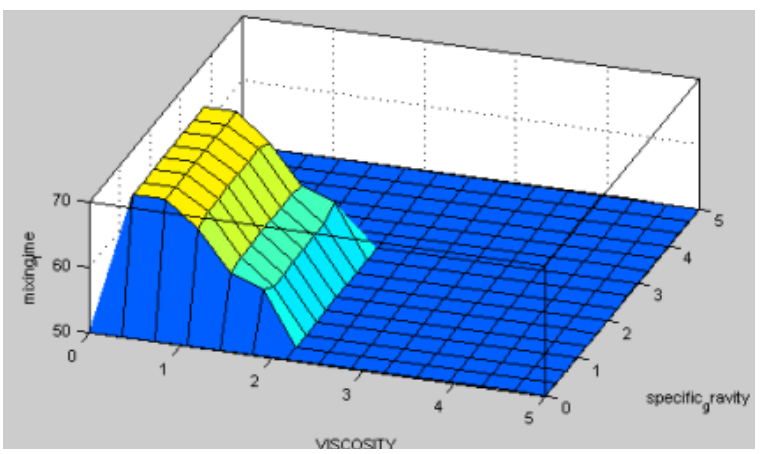

Fig. 7(d) Plot between specific gravity, viscosity and mixing time

Fig. 7(e) Shows that valve opening does not depend on the viscosity of the syrup it depends on specific gravity

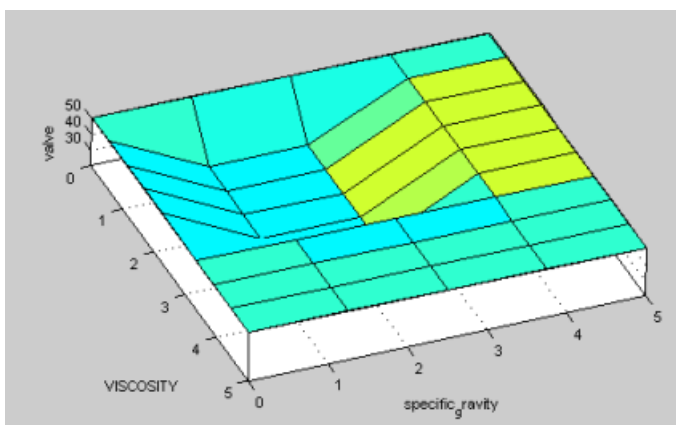

Fig. 7(e) Plot between specific gravity, viscosity and valve opening

Fig. 7(f) Shows that PH does not depend on viscosity it depends on specific gravity.

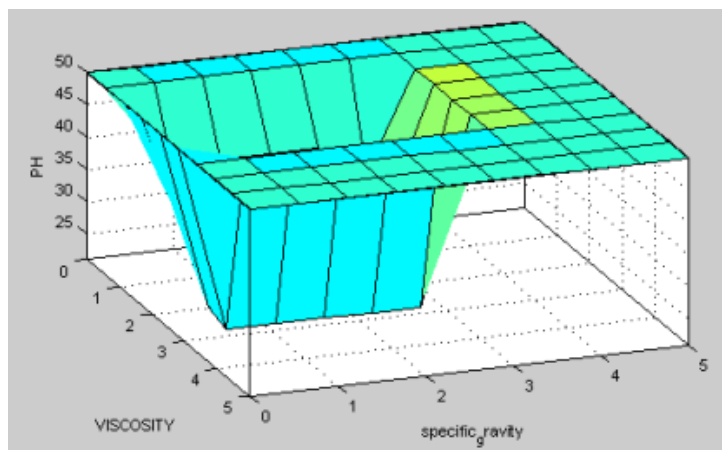

Fig. 7(f) plot between specific gravity, viscosity and the syrup PH

Fig. 7(h) Shows that mixing speed depends on the specific gravity of the liquid

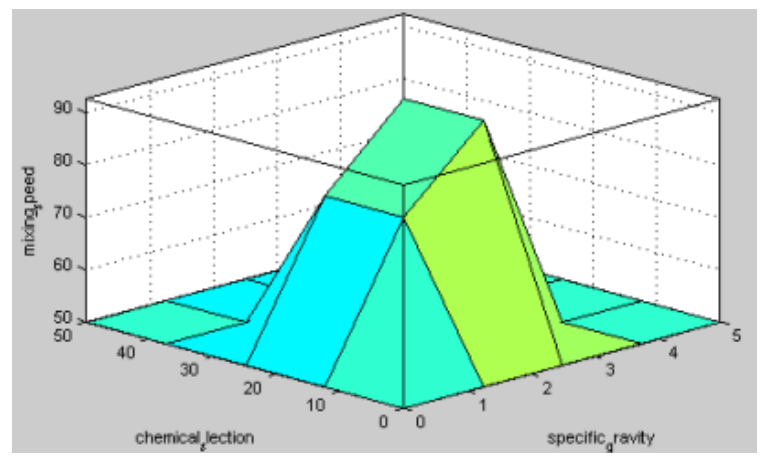

Fig. 7(h) Plot between chemical selection, specific gravity and mixing speed

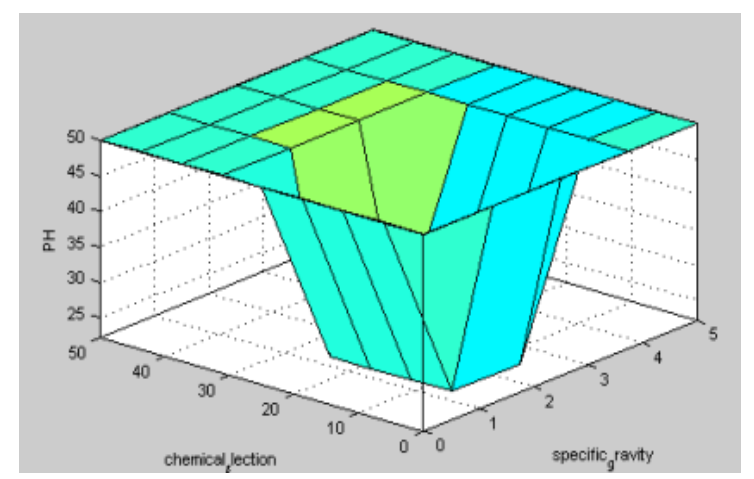

Fig. 7(i) Plot between chemical selection, specific gravity and $\mathrm{PH}$

Fig. 7(i) Shows that PH of syrup depends on specific gravity it does not depend on chemical selection. 


\section{CONCLUSION}

Proposed syrup manufacturing model is an industrial application of fuzzy time control discrete event system. Design model is very efficient and simple in their performance and has flexibility to adjust the input and output parameters easily according to the syrup requirement. Design model provides the satisfactory defuzzified values from MATLAB simulation, which shows the effectiveness of the approach. Proposed syrup manufacturing model provides stable state of syrup in small interval of time.

\section{REFERENCES}

[1] M. Abbas, M. S. Khan, and N. Ali, "Fuzzy Logic Based Hydro-Electric Power Dam Control System," International Journal of Scientific \& Engineering Research (IJSER), vol. 2, no. 6, pp. 9-16, 2011.

[2] W. H. Chen, S. Sung, and S. Y. Chen, "Biological hydrogen production in an aerobic sequencing batch reactor: $\mathrm{pH}$ and cyclic duration effects," Int J Hydrogen Energy, vol. 3, no. 4, pp. 227-234, 2009.

[3] Pharmacopoeia European, 5th edition, 2005 (609), 5.0 liquid preparation for oral use, EDQM - European Directorate for the quality of medicines, Strasbourg, France.

[4] A. Scheler, S. Saupe, S. Herre, and A. Fahr, "Preservation of Drug Preparations for Oral Administration," Journal of 10 Pharmaceutical Sciences, vol. 99, no. 1, pp. 357-367, 2006.

[5] P. Saraphirom and A. Reungsang, "Optimization of biohydrogen production from sweet sorghum syrup using statistical methods," Int. J Hydrogen Energy, vol. 35, no. 24, pp. 3435-3444, 2010.

[6] G. H. Anderson," Much ado about high-fructose corn syrup in beverages: the meat of the matter," Am J. Clin Nutr, vol. 86, no. 6, pp.1577-1578, Dec. 2007.

[7] M. S. Khan, "A proposed grinding and mixing system using fuzzy time control discrete event model for industrial application," I. A. Eng. , IMECS, vol. 2, pp. 1231-1236, 2009.

[8] S. Islam and Shakowat, "development of fuzzy logic controller algorithm for Air conditioning system," in proc. international conference on semiconductor electronics, IEEE, pp. 830-834, 2006.
[9] M. S. Khan, "Fuzzy time control modeling of discrete event system," in proc. 51 international conference on intelligent Automation and robotics, WCECS, pp. 683-688, 2008, U.S.A.

[10] Y. C. Ho, "Discrete event dynamic system analyzing complexity Performance in the modern word," IEEE, 1994.

[11] R. Tibshirani, T. Hastie, and J. Friedman, "The Elements of Statistical Learning Springer-Verlag," Heidelberg, 2001.

[12] R. Huq, G. K. I. Mann, and R. G. Gosine, "Behavior modulation technique in mobile robotics using fuzzy discrete event systems," IEEE Trans. Robotics, vol. 22, no. 5, pp. 903-916, 2006.

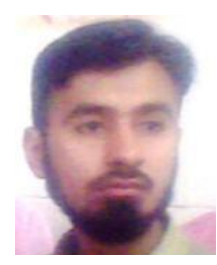

Syed Fazil Bin Farukh received M.S. degree in the field of electronics engineering from faculty of Engineering and Technology, International Islamic University Islamabad. He is currently availing a research fellowship at The GC University, Lahore, Pakistan and completed his M.S thesis in the field of control systems: with title "industrial application of fuzzy time control discrete event system". His research interests include control systems design and industrial applications.

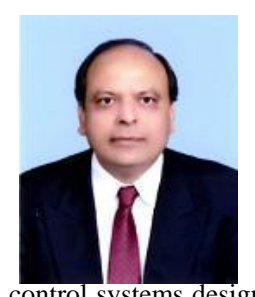

M. Saleem Khan is a director of computer science dept. at GC University Lahore, Pakistan. He completed his Ph.D. thesis in the field of control systems: design, simulation and analysis in local and distributed environment. $\mathrm{He}$ contributed his services on various projects in the field of Advanced Electronics and Communication. His Research interests include control systems design and industrial applications. He promoted a large team of Electronics researchers and organized this field in his country. Mr. Khan had also been served as a senior scientific officer in a classified defence research organization in his country. 